\title{
A Comparative Study of Saudi and International Journals of Applied Linguistics: The Move-Bundle Connection Approach
}

\begin{abstract}
Basim Alamri
King Abdulaziz University

Correspondence concerning this article should be addressed to Basim Alamri, English Language Institute, King Abdulaziz University, Jeddah, 21589, Saudi Arabia. E-mail: bmalamri@kau.edu.sa

The present study implemented a genre-based approach to analyze the rhetorical structure of English language research articles (RAs): specifically, the Introduction-Methods-ResultsDiscussion-Conclusion (I-M-R-D-C) sections. Next, lexical bundles (LBs) associated with patterns of moves were identified by applying a corpus-driven approach. The study analyzed two corpora of 30 RAs purposely selected from 16 peer-reviewed journals of applied linguistics published in Saudi Arabia and internationally during the years of 2011-2016. First, a genrebased approach was used to identify the move structures of RAs through analyzing different RA sections by different models. Next, lexical bundles associated with each identified move in each IMRDC section were analyzed using a corpus-driven approach, based on structural and functional taxonomies. The study findings showed that both corpora share similarities and differences related to rhetorical structures and lexical bundles. These findings have pedagogical implications for novice writers, graduate students, and English for Academic Purposes (EAP) instruction, including raising awareness of rhetorical structures and LBs in academic writing for publication, which could help produce more successful publishable research articles.
\end{abstract}

Keywords: corpus linguistics, cultural variations, genre-based approach, lexical bundles, rhetorical structure

\section{Introduction}

In academia, scholars and researchers have been using research articles (RAs) as the primary channel for distributing knowledge within academic discourse communities (Habibie \& Hyland, 2019). The participation of multilingual researchers in national and international academic journals enriches global knowledge with various perspectives on academic writing (Hyland, 2015). The publication of RAs across disciplines has increased in various local and international communities because publication plays a crucial role in academic success related to retention or promotion, especially for researchers around the globe (Friginal \& Mustafa, 2017).

Writing publishable research articles for scholarly journals is an intimidating task, especially for novice writers (Tardy, 2019). Writing for publication in certain disciplines requires specific academic writing techniques and skills in order to produce a research article that can be considered for publication in scholarly journals (Cocal \& De Vera, n.d.; Hyland, 2008a; Moldovan, 2011). Such techniques include an awareness of the rhetorical organization of texts and the ways that authors employ specific linguistic features in a targeted journal.

Clearly, academic writing encompasses several variations of styles and conventions that are unique to each discipline across different languages and cultures (Hyland, 2016). Since graduate students and novice writers may encounter difficulties in dealing with disciplinary academic discourse, there is a need to develop approaches to academic writing for publication courses (Xu, 2019). A genre-based approach is one of several approaches that helps novice writers fulfill their academic writing needs. The genre-based approach refers to the teaching of macrostructures and rhetorical organization of texts in an academic writing course (DudleyEvans, 1994; Swales, 1990). The other approach is a corpus-driven approach, in which researchers systematically 
identify formulaic language, multiword expressions, and the metadiscourse used by experts in their disciplines (Biber et al., 1999; Mizumoto, Hamatani, \& Imao, 2017).

The present study is inspired by several motivations, including the significance and novelty of the methods used for addressing the issues of cultural variation, the increased publication pressure on international scholars, and the underrepresentation of Saudi scholars in journals with an international reputation. According to Stefanowitsch (2018), corpus linguistic methods can be used to uncover some properties of certain cultures, such as the distribution of lexical items in a corpus. Cheng (2006) also asserts that implementing a genre-based approach in the classroom helps students "acquire conceptual and cultural frameworks to undertake writing tasks beyond the courses in which such teaching occurs" (p. 77). In fact, researchers and academics need to publish their work in well-established international journals for several reasons, including promotion. It is evident that these scholarly journals are highly competitive, which requires authors to have an advanced awareness of genre conventions and linguistic features as well as critical academic writing skills. In the Saudi context, researchers face increasing pressure to publish their work in reputable international journals in their respected fields, although few scholars have accomplished this job, especially in the applied linguistics discipline (Alamri, 2017). That being said, the underrepresentation of Saudi researchers in the international academic discourse community may be driven by a key factor. International journals have a certain rhetorical structure, writing style, and linguistic features that are different from the ones in local and national journals. Unfortunately, corpus investigations of Saudi English are scarce on these topics, especially on linguistic features (Fallatah, 2016; Mahboob \& Elyas, 2014).

The present study therefore aimed to explore the move patterns and lexical bundles in a corpus of 30 RAs from journals published in Saudi Arabia and internationally in the field of applied linguistics. To the best of my knowledge, there are no such studies that investigated all of the sections of research articles in applied linguistics in the Arab world, especially in the Saudi context. In the study, the first step involved analyzing RAs that follow the IMRDC format. Next, all four-word bundles associated with each move were identified and analyzed following Biber et al.'s (1999) structural and Hyland's (2008b) functional taxonomies. The analyses looked for possible cultural variations and relationships between moves, and frequently used lexical bundles in the IMRDC sections of RAs. The following subsections provide a brief explanation of move analysis and lexical bundles and the possible relationship between them, as well as an overview of genre and corpus linguistics investigations in Saudi Arabia.

\section{Genre and Move Analysis}

Swales (1990) defined genre as "a class of communicative events, the members of which share some set of communicative purposes" (p. 85). Hyland (2016) also described genre as "abstract, socially recognized ways of using language and represent how writers typically respond to recurring situations" (p. 120). In other words, a member of a discourse community employs several techniques through repeated exposure to recognize the common structural and linguistic features shared by experienced writers and scholars in the discourse community.

The work of John Swales has shifted the concept of genre analysis from analyzing genre as a pure linguistic unit to analyzing it as a discursive unit, by developing a new analytical tool named move analysis. According to Swales (2004), a move (M), which may contain one or more steps, is a discoursal segment that performs a unique communicative function. The term step refers to "a lower level text unit than a move that provides a detailed perspective on the options open to the writer in setting out the moves" (Dudley-Evans \& John, 1998, p. 89). Swales' genre analysis method is also known as the Creating A Research Space (CARS) model. According to the CARS model, the Introduction section includes three communicative purposes or moves and several steps associated with each move, which are used to realize the move: Move 1 is "establishing a territory," Move 2 is "establishing a niche,", and Move 3 is "occupying the niche."

Previous research has analyzed the genre of research articles in various disciplines, including sociology (Brett, 1994), applied linguistics (Pho, 2008), computer science (Posteguillo, 1999), and medicine (Nwogu, 1997). Specifically, three sections have drawn much of the researchers' attention: Abstracts (Bhatia, 1993), Introductions (Ozturk, 2007; Swales, 1990), and Discussions (Dudley-Evans, 1994; Holmes, 1997; Ruiying \& Allison, 2003). On the other hand, the following sections may need more investigation: Literature Reviews 
(Kwan, 2006), Methods (Cotos, Huffman, \& Link, 2017; Peacock, 2011), and Results (Brett, 1994). Furthermore, genre analysts have analyzed the four sections of RAs (IMRD) (Kanoksilapatham, 2005; Nwogu, 1997; Pho, 2008; Posteguillo, 1999).

\section{Lexical Bundles}

Biber et al. (1999) state that lexical bundles are "recurrent expressions, regardless of their idiomaticity and regardless of their structural status" (p. 990). Likewise, Hyland (2008b) defines lexical bundles as "words [that] follow each other more frequently than expected by chance, helping to shape text meanings and contributing to our sense of distinctiveness in a register" (p. 5). For instance, the following phrases are considered four-word lexical bundles: it is important to, is shown in figure, and are likely to be.

Lexical bundles have been widely investigated over the past three decades via corpus linguistics approaches in both spoken and written registers (Biber, 2009; Biber \& Gray, 2015; Hyland, 2008b; Pan, Reppen, \& Biber, 2015). For example, the frameworks established in the seminal studies of Altenberg (1998) and Biber et al. (1999) have been extensively employed in the literature. Both frameworks aim to identify and analyze frequency-based recurrent words and expressions in terms of discourse functions and grammatical features (Yoon \& Choi, 2015). Lexical bundle investigations have been conducted to serve several purposes, including describing register variations (Biber \& Barbieri, 2007; Hyland, 2012), expressions of different registers in various contexts (Ädel \& Erman, 2012), and different discourse functions of lexical bundles (Chen \& Baker, 2010; Cortes, 2013). These studies indicate that it is crucial for writers to be aware of linguistic features and how to employ them in their targeted discourse community in order to develop their academic writing.

\section{The Connection Between Lexical Bundles and Rhetorical Structure: Building Blocks}

According to Cortes (2013), lexical bundles and moves have more similarities than differences. That is, both concepts are seen as building blocks of academic discourse (Cortes, 2013). Hyland (2008b) considers lexical bundles to be "important building blocks of coherent discourse and characteristic features of language use in particular settings" (p. 8). Similarly, Biber and Barbieri (2007) point out that lexical bundles are "important building blocks of discourse in spoken and written registers" (p. 263). Move types are considered the "main building blocks" of a genre (Biber, Connor, \& Upton, 2007, p. 53). To investigate the relationship between lexical bundles and rhetorical structure, Cortes (2013) analyzed a corpus of RA Introduction sections from 13 disciplines with one million words. Cortes first identified lexical bundles associated with each move and then classified them based on their discoursal functions. The analysis indicated that some LBs were exclusively connected to a certain move or step, and other bundles were employed to open certain rhetorical moves in the Introduction section.

\section{Background: Genre and Corpus Studies in Saudi Arabia}

In Saudi Arabia, genre analysis studies and corpus linguistic literature seem relatively scarce. For genre analysis investigation, Alqahtani's (2006) study appears to be the earliest of the genre studies that carried out a contrastive rhetoric analysis between Arabic and English RA introductions. Using the CARS model, Alqahtani (2006) analyzed 15 RA introductions, which were sorted into three groups: Arabs educated in the U.S., Arabeducated Arabs, and U.S. Native English speakers. The findings indicated that the three-way comparisons showed more differences than similarities at macrostructure and the move/step levels.

In addition, there are three studies that carried out comparative analyses of Arabic and English RA abstracts (Alhuqbani, 2012; Alotaibi, 2013; Fallatah, 2016). Alhuqbani (2012) carried out a cross-cultural analysis to examine a corpus of 30 RA Arabic abstracts and 30 RA English abstracts in the police and security science disciplines by using three models: those of Swales (2004), Bhatia (1993), and Hyland (2000). The study reported differences in the Swales' model, whereas both corpora were similar in the other two models. Similarly, Alotaibi (2013) employed the CARS (Swales, 2004) and Hyland models (2000) to investigate the relationship between the Abstract and Introduction sections. The corpus included 20 English and Arabic RA abstracts and introductions from two disciplines: sociology and educational psychology. The results showed several differences across languages and disciplines. Moreover, in a comparative study, Fallatah (2016) analyzed English and Arabic RA abstracts written by three different groups: a Saudi writers group with 37 English RA abstracts, 
Saudi writers with 27 Arabic RA abstracts, and international writers with 29 English RA abstracts. Using the Swales and Feak framework (2009), the Saudi English RA abstracts showed differences in several aspects compared with their English international RA counterparts. The Saudi English RA abstracts "show[ed] more move presence fluctuation; verbosity; move cyclicality; excessive use of citation, acronyms, and listings; and multi-paragraphing" (p. 368).

Finally, for RA sections only written in Arabic, Alhuqbani (2013) investigated RA abstracts, and Alotaibi and Pickering (2013) analyzed RA Introduction sections. To identify the move patterns of the Arabic RA abstracts in four disciplines (i.e., medicine, law, police, and linguistics), Alhuqbani (2013) implemented Hyland's (2000) and Bhatia's (1993) models to analyze 10 abstracts from each discipline. The analysis revealed that the four disciplines varied in the move structure of the two models, and medicine was exactly like the structures mentioned in the models. Following Swales' (1990) CARS model, Alotaibi and Pickering (2013) carried out a cross-disciplinary investigation to analyze 20 RA Arabic introductions and compared them with international ones. The results revealed that the Arabic RA introductions and the American English ones were different in terms of the employment of the following rhetorical moves: Establishing a Territory, Establishing a Niche, and Occupying the Niche.

As for corpus linguistics, studies of lexical bundles in applied linguistics in Saudi Arabia appear to be rare. Therefore, in Saudi Arabia, there exists a substantial gap in genre analysis and corpus linguistics investigations in the research literature, especially in theoretical and applied linguistics disciplines. In fact, the majority of previous studies in the Saudi context investigated either the Abstracts or Introduction sections, but none of them have investigated the remaining sections of the research articles. The present study thus hopes to address cultural variations between the Saudi and international corpora in the whole RA sections, i.e., IMRDC. As advised by Nwogu (1997), in addition to cultural variations, writers, as well as readers, could benefit from analyzing complete sections of research articles to gain an understanding of the organizational structure of such articles (Alamri, 2017). In short, the present study aims to investigate the following research questions:

1. What similarities and differences exist in rhetorical structures used in English-language articles published in journals of applied linguistics in Saudi Arabia and internationally?

2. What similarities and differences exist in lexical bundles used in each move of English-language articles published in journals of applied linguistics in Saudi Arabia and internationally?

\section{Corpora and Methodology}

\section{Description of the Corpora}

The corpora selected for investigation in the present study comprised 30 English language research articles derived from 16 journals published in Saudi Arabia and internationally in the field of applied linguistics, with eight journals from each corpus (Appendix A shows the list of research articles). First, Nwogu's (1997) criteria for selecting journals (i.e., representativeness, online accessibility, and reputation) were used to increase the degree of comparability between both corpora. Furthermore, the international journals were selected on the basis of the impact factor for the year 2017 according to the Journal Citation Reports (JCR). The Saudi journals, however, were chosen based on their reputation being recognized by university promotion committees and among professors of applied linguistics since there is no journal ranking system in Saudi Arabia. Second, the research articles were selected based on the following criteria: (a) the RAs had to have complete (IMRDC) sections, and (b) the articles were published between 2011-2016. Finally, through examining the authors' biographies on the universities' websites, for the Saudi corpus, authors who were native speakers of Arabic affiliated with Saudi Arabian universities were identified. In the international corpus, on the other hand, most of the authors were affiliated with universities located in the United States, Europe, and Canada. Both qualitative and quantitative analyses of rhetorical moves/steps and lexical bundles were conducted. The total number of words in both corpora is presented in Table 1. 
Table 1

The Corpus of the International and Saudi Journals

\begin{tabular}{lccc}
\hline & No. of RAs & No. of journals & No. of words \\
\hline Saudi corpus & 15 & 8 & 100,947 \\
International corpus & 15 & 8 & 126,187 \\
Total & 30 & 16 & 227,134 \\
\hline
\end{tabular}

\section{Conducting Genre Analysis}

The first phase of analysis involved identifying move structures. After compiling the corpora, genre analyses were employed to analyze the move structures of RAs. In particular, five models were used to examine the five RA sections. Introduction sections were analyzed using Swales' (2004) three-move CARS model, Methods sections were examined using Peacock's (2011) seven-move model, and the Results-Discussion-Conclusion sections were analyzed using Ruiying and Allison's (2003) three models. These models were chosen for the present study because of their wide use in different disciplines and because they are considered comprehensive, especially in the applied linguistics field. Since the central notion in the analysis of both corpora was communicative purpose, a top-down approach to corpus analysis was adopted. That is, each move was analyzed based on the most salient function found in a sentence or couple of sentences (Holmes, 1997; Ozturk, 2007).

The procedures of analyzing 30 RAs was conducted in several phases. The first step was the analysis of the overall structure of each RA (i.e., headings), followed by a thorough reading and examination of each sentence in each section to identify the presence/absence of move/step, move frequency, move structure, and move cyclicity. The results of the analysis were then closely examined and compared to identify possible cultural variations between both corpora. The threshold frequency of a move was set to $70 \%$ for a move to be considered conventional; if the frequency fell below $70 \%$, the move was considered optional in the corpus. In addition, for reliability purposes, an experienced coder in move analysis pursuing a Ph.D. in TESOL was recruited. A twohour face-to-face training session was conducted with the coder to explain the procedures of conducting and using the coding schema and protocol for each section of the research article in the corpus. After that, the coder was asked to analyze six random RAs (3 RAs, $20 \%$, from each corpus) in a month. We then discussed the process of the analysis until we reached an agreement rate across all five sections via a Cohen Kappa value of 0.91 and a percentage of agreement of $94.76 \%$. As for the intra-rater reliability, the author randomly re-coded 3 RAs (20\%) from each corpus three months after the initial coding.

\section{Lexical Bundle Identification and Analysis}

The bottom-up approach (i.e., corpus analysis) was employed to identify lexical bundles found in each move. The identification and classification of the bundles comprised several criteria: the range cut-off point of LBs was to be present in at least two research articles in each corpus to guard against the idiosyncrasies of individual writers, only 4-word bundles were extracted from the corpus due to the fact that these bundles are "the most researched length for writing studies" and are "often within a manageable size (around 100) for manual categorization and concordance checks" (Chen \& Baker, 2010, p. 32). All research articles were cleaned by removing titles, tables, section headers, graphs, footers, paper codes, and reference lists. Lastly, bundles that did not have a function or rhetorical purpose were excluded (e.g., for teaching EFL skills, in the target language).

The identification of LBs process involved creating sub-corpora based on the results of the move analyses in the first phase; each identified move was entered in a plain text document resulting in a total of 780 plain text documents. All the identified moves were grouped and listed based on the corpus the moves represented (Alamri, 2017). Following that, AntConc 3.4.3w software was used to extract the LBs from each identified move. Then the identified bundles were examined for appropriate context-dependent content (e.g., the second language acquisition process) and overlapping bundles, following Chen and Baker's (2010) recommendations. In other words, to guard against inflated results, any overlapping bundles were merged into one longer bundle (e.g., it has been suggested and has been suggested that) (Chen \& Baker, 2010). For the purpose of grammatical classification, the grammatical annotations of the extracted bundles were generated via Multi-Dimensional Analysis (MDA) Tagger software. Finally, the retrieved bundles were analyzed structurally based on Biber's and his colleagues taxonomy (Biber, Conrad, \& Cortes, 2004), and functionally by the taxonomy developed by 
Hyland (2008b), see Appendices B \& C. Biber et al's (2004) taxonomy includes three broad structural categories: NP-based (e.g., the end of the), PP-based (e.g., in the case of), and VP-based bundles (e.g. it is clear that). In addition, Hyland's (2008b) taxonomy includes three broad categories: Research-oriented bundles (e.g., the purpose of the), Text-oriented bundles (e.g., as a result of), and Participant-oriented bundles (e.g., Stance: are likely to be, Engagement: as can be seen).

\section{Results and Discussion}

The following sections present the results of move and bundle analyses, accompanied by discussions of examples derived from both corpora.

\section{General Findings}

The study findings of the genre-based approach analysis showed similarities in the Introduction, Discussion, and Conclusion sections, and differences in the Methods and Results sections. As shown in Table 2, the analysis of the corpus-driven investigation yielded 205 (with 597 tokens) lexical bundles in the Saudi dataset and 145 (358 tokens) in its international counterpart. Both corpora shared only 22 out of 350 types of bundles. The following subsections will elaborate on some cultural aspects, as well as the similarities and discrepancies in both corpora, with examples from the Saudi corpus (labeled as S) and the international corpus (labeled as I).

Table 2

Total number of words in each section of both corpora

\begin{tabular}{lcccccccc}
\hline \multirow{2}{*}{ Sections } & \multicolumn{4}{c}{ International corpus } & \multicolumn{3}{c}{ Saudi corpus } \\
\cline { 2 - 9 } & Types & Tokens & TTR & Total \# of words & Types & Tokens & TTR & Total \# of words \\
\hline Introduction & 43 & 103 & 0.42 & 30,758 & 95 & 289 & 0.33 & 39,804 \\
Methods & 28 & 69 & 0.41 & 27,094 & 18 & 42 & 0.43 & 15,247 \\
Results & 23 & 57 & 0.40 & 30,790 & 38 & 134 & 0.28 & 21,132 \\
Discussion & 48 & 123 & 0.39 & 27,428 & 34 & 90 & 0.38 & 17,159 \\
Conclusion & 3 & 6 & 0.50 & 6,609 & 20 & 42 & 0.48 & 6,105 \\
Total & 145 & 358 & 0.41 & 122,679 & 205 & 597 & 0.34 & 100,952 \\
\hline
\end{tabular}

\section{Moves and Lexical Bundle Analysis in both Corpora}

\section{Introduction Section}

The present study found that the three moves (i.e., Move 1: Establishing a Territory, Move 2: Establishing a Niche, and Move 3: Presenting the Present Work) were conventional; these moves occurred in all RA introductions in both corpora (100\%). Previous studies have reported similar findings (Amnuai, 2012; Ozturk, 2007; Pho, 2008; Swales, 1990). Moreover, the Saudi corpus exhibited two of the most preferred move structures (i.e., M1M2-M3-M2 and M1-M3-M2-M3), whereas the international dataset showed the following pattern: M1-M2-M3M2-M3. Move 3 was the most cyclical in both datasets, then Move 2, and lastly, Move 1. Obviously, Move 3, with its seven steps, is the most common strategy used by authors to increase explicitness and announce the present research descriptively and/or purposively (Pho, 2008).

Noticeable cultural aspects were identified at the step level in the Introduction sections. First, the function of the Indicating a gap Step seemed different between the national and international datasets. In other words, the absence of any direct criticism of the work of others appeared to be problematic for the authors in the Saudi journals. Alternatively, the authors referred to cases where the research topic being investigated was limited or did not exist. This kind of absence was documented in different contexts, including Saudi Arabia (Alotaibi \& Pickering, 2013; Al-Qahtani, 2006), and other EFL contexts (e.g., Hirano, 2009). Cultural traits concerning the communication of knowledge could be a reason for this; that is, some authors in the Saudi corpus may have wanted to avoid the direct criticism of the work of others, thinking that criticism is inappropriate or less acceptable, which may engender negative attitudes from other researchers (Hirano, 2009). In addition, although 
no cultural trait was found, unlike the authors in the international corpus, some authors in the Saudi corpus not only established the niche by adding to what was already known and/or indicating a gap, but the authors also tended to provide justifications (Step 2) to convince the readers.

Second, the employment of integral and nonintegral citations appeared to be different in both corpora. In the integral citations, the name of the researcher or author occurred at the beginning or in the sentence itself, for instance, Hyland (2008) believes that.... The nonintegral citations, however, refer to the ones in which the name of the researcher or author appears in parentheses at the end of the sentence or when referring to authors by another device or another convention (Swales, 1990). The Saudi corpus encompassed more (291 or 54\%) integral citations compared to nonintegral ( 249 or $46 \%$ ) ones. On the other hand, the international corpus was dominated by nonintegral citations (296 or $62 \%$ ) compared to integral citations (184 or 38\%). In fact, being unaware of the academic usage of both types of citations may be due to a lack of analysis and synthesis skills, which was noticed when reporting previous research in the Saudi corpus (Thompson \& Tribble, 2001).

Third, promotional aspects were found in Step 6 of both corpora, stating the value of the present research. The promotional aspect is a space for authors to signal the significant and innovative aspects of their work (Hyland \& Tse, 2005; Swales, 2004). The findings indicated that (86.6\%) of the authors in the Saudi corpus preferred evaluating their research compared to their international peers (26.6\%). The main function of this step used by the authors was to convince readers that the authors' arguments needed to be read and taken seriously (Hyland \& Tse, 2005; Swales, 2004). Given that the authors in the Saudi corpus were native speakers of Arabic, stating the value of the research perhaps stemmed from the Arabic culture and its writing style (Alamri, 2017; Alharbi \& Swales, 2011; Fakhri, 2004). Example (1) is derived from the Saudi corpus, and it illustrates this promotional feature.

\section{(1) This study is a pioneering study in the sense that it is the first of its kind that investigates .... (S4)}

As for the lexical bundle analysis of the Introduction sections, all three moves encompassed 138 LBs: 43 bundles (103 tokens) appeared in the international corpus, and 95 bundles (289 tokens) appeared in its Saudi counterpart. Specifically, the Establishing a territory move contained six LBs in the Saudi dataset compared to five LBs in the international one, and two bundles were shared by both corpora (i.e., on the other hand-one of the most). Furthermore, the Establishing a niche move had most of the identified bundles, with 73 LBs elicited in the Saudi corpus, while 31 LBs were elicited in the international one. The Presenting the Present Work move included 30 and seven LBs in the Saudi and the international corpora, respectively. A possible explanation for the significant difference in lexical bundles between both corpora could be attributed to the lengthy nature of the Introduction section in the Saudi corpus compared to the international corpus. In other words, a closer look at both corpora showed that about $40 \%$ of the Saudi corpus (39,804 words, see Table 2 for more details) was in the Introduction sections, whereas the corresponding sections of the international corpus comprised only $25 \%$ (30,758 words). These findings perhaps indicate that authors in the Saudi corpus tended to focus more on providing a detailed literature review rather than a concise and synthesized one. Therefore, the lengthier texts employed more lexical bundles and signals to guide readers through the text (Pan et al., 2015).

Regarding structural classification, all three moves in the Introduction in both corpora shared three structural categories (i.e., VP-based, PP-based, and other) in similar proportion. However, while the authors in the international corpus employed (17\%) NP-based bundles, their peers in the Saudi journals employed almost double that (34\%), which deserves more explanation. First, the overuse of NP-based bundles could be related to the inadequacy of some writers in terms of using NP structures. In addition, Halliday (1989) argued that translating from L1 to L2 when writing a text may lead to the overuse of noun phrases (Gungor \& Uysal, 2016). Lastly, given that the Introduction sections in the Saudi journals were lengthy and had a larger number of lexical bundles compared to their International counterparts (289/103 tokens), the size of the corpus could be another reason for the overuse of the NP-phrase, as stated in the previous paragraph.

An analysis of functional classification revealed several variations between the two datasets. The Saudi corpus used more research-oriented bundles (56\%), followed by text-oriented (36\%) and participant-oriented (8\%) ones. In the international journals, on the other hand, the authors employed more text-oriented bundles (50\%), followed by research-oriented $(27 \%)$ and participant-oriented $(23 \%)$ ones. Hyland $(2008 \mathrm{~b})$ states that textoriented bundles are heavily used in international scholarly journals in applied linguistics compared to local 
journals in order to "provide familiar and shorthand ways of engaging with a literature, providing warrants, connecting ideas, directing readers around the text, and specifying limitations" (p. 16). However, some local journals, like Saudi journals, may have fewer text-oriented bundles compared with research-oriented ones, which could be associated with the non-native authors' lack of awareness of syntactic and lexical knowledge (Gungor \& Uysal, 2016). Additionally, the use of stance and engagement (i.e., participant-oriented) bundles was far more frequent in the international corpus $(23 \%)$ than in the Saudi $(8 \%)$ one, even though the Saudi corpus contained a larger number of bundles (95 types/289 tokens). The main function of stance and engagement features is to provide interpretations of propositions and to engage readers with the text. The authors in the Saudi corpus explicitly avoided stating their authorial stance in their arguments, perhaps because they felt uncomfortable evaluating their own work and arguments. Stance and engagement features play a vital role in the international discourse community, especially in highly ranked journals (Hyland, 2008b). For example, the bundle are likely to be appeared in the international corpus 12 times, while occurring only two times in the Saudi counterpart, as shown in Examples (2) and (3), respectively:

(2) Such concerns are likely to be all too familiar for teacher trainers in various contexts. (I14)

(3) The immediate goal in reading and in the processes exercised by the reader are likely to be affected by both the reader's cognitive style and by training in processes for studying text material. (S2)

\section{Methods Section}

The results identified three moves in the Saudi corpus (i.e., M4: Overview - M7: Subject/Material - M8: Procedures) and four moves in the international corpus (i.e., M5: Location - M7- M8- M10: Data analysis). In addition, the international corpus did not incorporate M6 Research Aims/ Hypotheses/ Questions and M9 Limitations. The weight given to the Methods section in both corpora was not the same. That is, the Methods sections in the Saudi dataset were relatively shorter and missing some details, specifically in M10 Data analysis. A number of Saudi authors' may not have been be fully aware of the importance of presenting a thorough description of the data analysis and procedures to establish credibility in the Methods section (Cotos et al., 2017), which could be the main reason for the desk-rejection in scholarly journals. Example 4 of Move 10, below, shows a very general description of the data analysis, which can certainly lead to confusion and/or misunderstanding of the procedures of the data analysis.

(4) A three-way analysis of covariance (ANCOVA) was used to answer the questions of the study. More specifically, ANCOVA was used to find out if there were any statistically significant differences at (0.05) between students' achievement mean scores according to the way of instruction, stream of study and the interaction between them. (S10)

As for move patterns, while the Saudi corpus did not have a frequency pattern, the international corpus displayed the following pattern (M7-M5-M7-M8-M10) as the most frequent move structure. In addition, the analysis produced a modified model comprised of two related moves that usually occurred together, i.e., Location and Subject. Therefore, these two moves were combined into one move called Describing the instruments of the study.

In terms of lexical bundles, the international corpus included 28, whereas the Saudi counterpart had 18, and M7 (Subjects/Materials) comprised most of the bundles found in both corpora; 13 were in the international corpus and 10 were found in the Saudi corpus. Both sets of data shared three bundles (in the present study, they were asked to, the purpose of the). Moreover, M6 (Research Aims/ Hypotheses/Questions) and M9 (Limitations) did not have bundles in any of the corpora. The rest of the moves in the Methods sections included several bundles in both corpora, except Move 4 (Overview), which had four LBs in the Saudi dataset only.

The results of the structural and functional analyses were similar for both corpora. Structurally, both corpora employed predominantly noun and prepositional phrases, $48 \%$ of the bundle tokens in the Saudi corpus and $71 \%$ in the international corpus. The heavy uses of these phrases could be attributed to these phrases exhibiting high informational focus (Biber \& Conrad, 1999; Pan et al., 2015). In addition, the functional analysis showed similarities between both corpora, with one difference: that is, the international corpus frequently used participant-oriented bundles compared with no such uses in the Saudi corpus. Both corpora employed procedural bundles in Moves 7, 8, and 10 due to the functions that these bundles represent, such as to present study procedures or to quantify a study. Example (5) below includes a bundle from the international to express 
the quantity of something (i.e., courses). Example (6) derived from the Saudi corpus provides a bundle used to refer to data collection procedures.

(5) During their teacher training program at the university, the participants studied a wide range of courses related to foreign language teaching methodology... (I14)

(6) Data collection was conducted in the school setting, employing normal procedures, and on a regular school day during the second semester of 2007. (S7)

\section{Results Section}

The Results sections displayed three conventional moves in both corpora: M11: Preparatory information; M12: Reporting results; and M13: Commenting on results. While both corpora did not have M16: Deductions from the research, the international corpus did not have Move 15 (Evaluating the study). These results were consistent with previous studies carried out in applied linguistics (Pho, 2008; Ruiying \& Allison, 2003). These studies and others in different disciplines, e.g., medicine (Nwogu, 1997), indicated that the main purposes of the Results section include reporting results and commenting on them. Furthermore, M11 tended to be the most cyclical and was used more by authors in the Saudi journals (93\%) compared to their international peers (73\%). It is obvious then that authors in the Saudi journals preferred providing preparatory information to remind and guide readers.

In terms of lexical bundles, the Saudi corpus exceeded the international counterpart in number; 38 bundles and 23, respectively. Four LBs were shared by both corpora in M12 (Reporting results) (i.e., the majority of the, in each of the, statistically significant difference between, the results of the). Moreover, M11 (Preparatory information), M13 (Commenting on results), and M14 (Summarizing results) incorporated fewer bundles because these moves were used in a limited manner in both datasets, whereas there were no LBs in M15 (Evaluating the study) in both corpora.

Overall, both corpora shared similar structural and functional classifications. In the structural analysis, the main difference reported in the analysis was the heavy use of passive verb+prep. phrase fragments in the international corpus (e.g., can be seen in, are presented in table) compared to its Saudi counterpart. The main purpose of this phrase is to present the results of the study. It is worth mentioning that the Saudi corpus displayed the longest bundle found in the literature so far (i.e., it is clear from the findings of the study that), which appeared in M14 and belonged to anticipatory it + verb/adjective phrase. Cortes (2013) and Biber and Conrad (1999) also reported longer bundles. For example, Cortes (2013) identified the longest bundle in her study: the remainder of the paper is organized as follows.

In the functional analysis, the overuse of resultative signals was the main difference between the two datasets. Specifically, the resultative signal bundle the results of the had 3 tokens in the international corpus and 11 in the Saudi. This result can be interpreted in two ways. First, the authors in the Saudi journals could be proficient and aware of how to use these bundles efficiently (Pérez-Llantada, 2014). Second, these authors might have a limited resultative signals repertoire. However, their peers in the international journals preferred reporting their results by employing different bundles. In Example (7) from the international dataset, the author used was found in the bundle to report results of the study in M12 (Reporting results). Next, in Example (8) derived from the Saudi corpus, the sentence encompasses three different functions: resultative signals (i.e., the results of the), procedures bundles (i.e., statistically significant differences among), and stance features (be attributed to the).

(7) however, no statistical difference was found in the rate of textual plagiarism. (I4)

(8) The results of the two-way MANOVA are shown in Table 5 above, and they reveal statistically significant differences among the EFL Preparatory Year students' literal and inferential reading comprehension achievements that can be attributed to the interaction between the teaching method and the subjects' preferred learning styles. (S2)

\section{Discussion Sections}

The Discussion sections included two conventional moves in the international corpus (i.e., M18: Reporting results and M20: Commenting on results) and only one move in its Saudi counterpart (i.e., M20). In addition, the most frequently occurring move in all of the Discussion sections was M20, indicating that this move is necessary 
for discussing the findings of the study (Le \& Harrington, 2015; Pho, 2008; Ruiying \& Allison, 2004).

The analysis of M18 (Reporting the results) in both datasets merits a discussion. As stated earlier, this move was conventional in the international corpus (93\%) and optional in its Saudi counterpart (60\%). The finding from the Saudi corpus was inconsistent with most of the previous studies that indicated the conventional nature of this move (Amnuai \& Wannaruk, 2013a; Pho, 2008; Ruiying \& Allison, 2004). One possible interpretation might be that some writers did not want to be redundant, repeating similar findings from the Results sections. Instead, the authors employed M19 Summarizing results. A closer look at the Results sections in the Saudi corpus indicated that the matching move (i.e., M18: Reporting the results) was conventional (93\%). Pedagogically speaking in global context, it can be concluded that a typical Discussion section needs to encompass two conventions: M18 (Reporting the results) and M20 (Commenting on results).

Overall, the analysis of move patterns did not reveal any patterns. The analysis, however, showed that there was a highly cyclical sub-pattern, i.e., M18-M20. This sub-pattern occurred almost in and in-between every pattern in both corpora, mirroring the findings of Ruiying and Allison's (2004) in applied linguistics, Dudley-Evans (1994) in science, and across disciplines in Holmes (1997).

As for lexical bundles, the analysis showed that the international corpus had $48 \mathrm{LBs}$, while its Saudi counterpart contained 34 LBs. There were five bundles shared by both corpora: at the same time, the results of the/this, it is important to, on the other hand. The majority of bundles in both corpora were located in M18 (Reporting results) and M20 (Commenting on results): the international corpus had 30 LBs in M20 and 12 LBs in M18. The Saudi corpus, on the other hand, included 23 LBs in M20 and 6 in M18. However, no bundles were observed in M17 (Background information) and M21 (Summarizing the study). The most frequent bundles included in terms of the, the results of the, a significant difference in, and in the present study.

The structural analysis revealed a high degree of similarities between both corpora. It is obvious that lexical bundles were found in all categories, with two exceptions: the adverbial clause fragment in the international corpus, and the pronoun/noun phrase + be (+...) in the Saudi corpus. When I compared the overlapping moves (Reporting results) located in the Results and Discussion sections, the comparison showed that this move had more bundles when it occurred in the Results section compared with when it was found in the Discussion sections. This finding indicated that some bundles have several functions in academic prose (Biber \& Conrad, 1999; Hyland, 2008b).

As for the functional analysis, the findings showed that the international corpus relied heavily on text-oriented bundles (50\%). The Saudi corpus, on the other hand, depended on research-oriented bundles. It is evident that the authors in the international journals employed text-oriented bundles for several functions including engaging readers, specifying limitations or cases (e.g., in the case of), connecting ideas (e.g., in terms of the), and discussing literature (Hyland, 2008b). The use of framing signal bundles in both corpora also seemed different. That is, the main function of these bundles is to situate arguments through specifying limiting conditions. Interestingly, while the Saudi corpus did not have any framing signal bundles, the international counterpart included five types (12 tokens) in M20 (Commenting on results). Additionally, M18 (Reporting results) incorporated four bundles ( 8 tokens) and one bundle (3 tokens) in the international and Saudi corpora, respectively. According to Hyland (2008b), the lack of employing framing signal bundles in the Discussion sections indicates that the authors were not fully aware of the crucial roles these bundles have in academic writing. Examples (9) from the international corpus and (10) in the Saudi corpus below represent sentences that have bundles with different functions.

(9) The results of our study largely support the findings of the psycholinguistic studies reviewed at the beginning of this article with respect to the effect of age... (I1)

(10) Furthermore, all of the teachers frequently expressed confidence in their ability in teaching reading comprehension to Arab EFL learners as a result of their shared linguistic and cultural qualities with the students in terms of the reading culture. (S12)

\section{Conclusion Section}

All moves and steps appeared in the Conclusions sections in both corpora. Specifically, both corpora shared M26 (Deductions from the research) as a conventional move. In addition, M24 (summarizing the study) was 
conventional in the international corpus, and the conventional move in the Saudi was M25 (Evaluating the Study). The most frequent move was M26 followed by M24 as found in Moritz, Meurer, and Dellagnelo's (2008) study. To elucidate, in the Conclusion section, some writers preferred focusing more on recommending further research and pedagogical implications then evaluating their studies. In other words, the authors wanted to establish credibility for their studies (Morales, 2012; Sandoval, 2010). This result contradicted the majority of the previous studies in the literature on applied linguistics, where these studies reported that the most frequently occurring move in the Conclusions sections was M24 (Amnuai \& Wannaruk, 2013b; Morales, 2012; Ruiying \& Allison, 2003; Vuković \& Bratic, 2015).

Move 25 was the least frequent in the Conclusions sections because this move overlapped with the one in the Discussion sections; therefore, some authors employed this move in the previous section. In addition, a careful examination of M25/Step 2 revealed that some writers in the Saudi corpus were more hesitant to present limitations about their studies, which can be a result of cultural traits. On the other hand, the authors in the international journals seemed more open to mention the limitations of their studies. This could be related to the fact that some cultures may perceive limitations negatively as a criticism or even a self-criticism (Itakura \& Tsui, 2011).

Four move patterns were identified in both sets of data. The most frequent pattern was linear and chronological (M24-M25-M26), followed by M24-M26. The Saudi corpus included two more move patterns: M26-M25-M26 and M26. Furthermore, the sub-pattern M25-M26 was the most cyclical in the Conclusions sections. These results were consistent with those previous reported (Adel \& Moghadam, 2015; Ruiying \& Allison, 2003). For pedagogical purposes, all three moves (i.e., M24, M25, and M26) are necessary when writing a Conclusions section in applied linguistics.

For lexical bundles, both corpora incorporated 23 bundles, with most of them found in the Saudi corpus (20 LBs). The majority of the bundles in the Conclusions sections were located in M26 (Deductions from the research). Apparently, the authors in international journals preferred using three-word bundles compared to their Saudi peers who preferred four-word bundles.

The structural and functional classifications seemed to be limited because the Conclusions sections were relatively short. The average number of words was 440 in the international dataset and 407 in its Saudi counterpart. In the structural analysis, both corpora displayed VP-based bundles, as in are recommended to do. In the functional analysis, the participant-oriented bundles dominated in both datasets. The authors usually employed stance and engagement features to conclude their articles, recommending future investigations and drawing pedagogical implications. Such features included should try to be, carry out further research, future research could examine. Below are two examples (11) and (12) from the international and Saudi datasets, respectively:

(11) Finally, future research could examine abstract nouns in both countable and noncountable contexts... (I2)

(12) In light of the results of the study, the researcher recommends that EFL writing skills should be taught through the whole language approach. (S1)

\section{Conclusion}

In the present study move patterns and associated lexical bundles were investigated for each move of the English-language RA IMRDC structure published in Saudi Arabian and international journals in applied linguistics. The findings reported in the present study showed similarities and differences between both corpora regarding move patterns and lexical bundles, revealing cultural variances. The major similarities in both corpora are summarized as follows: 1) all rhetorical moves in Introductions, Discussions, and Conclusions sections appeared in both corpora; 2) Results and Discussions sections had a highly cyclical structure (i.e., M18 and M20); 3) both corpora shared similar structural classifications, especially NP-based and PP-based lexical bundles were found across all sections, except the Conclusions section; and 4) the extensive use of text-oriented bundles was noted in Discussions section (e.g., the extent to which, as discussed in the); and 5) the international corpus conformed mostly to RA conventional headings, except the Conclusions section. The differences, on the 
other hand, included: 1) rhetorical moves in Methods (M4 and M10) and Results sections (e.g., M11 and M15); 2) the functional classification of lexical bundles, especially research-oriented and participant-oriented bundles; 3) several linguistic features in the international corpus (i.e., stance \& engagement), compared with fewer features in the Saudi dataset (i.e., promotional aspects); and 4) the Saudi corpus deviated from RA conventional headings in the MRDC sections.

A key finding related to these variances needs to be highlighted. That is, the rhetorical structure analyses in the Saudi corpus shows that the articles adopted some unique rhetorical shapes and that they did not simply follow the typical rhetorical structures of the international corpus. In other words, the move patterns created by authors in the Saudi journals exhibited the articulation of some moves through hybrid and nonlinear patterns (e.g., cascading, chain, and focalizing structures) with a particular textual complexity in the Methods, Results, and Discussion sections. Clearly, the voices of the authors in the Saudi dataset can be considered variations of English or "hybrid voices" (Mauranen, 2007) unique to the Saudi set of data. Therefore, these unique hybrid rhetorical patterns reshape and display numerous English rhetorical structures in innovative and creative ways (Lorés-Sanz, 2016). According to Hyland (2004), the awareness of cultural variations in academic writing exhibits a sense of genre knowledge, but he cautions that "deviations are acceptable to the extent that they do not cancel out function or appropriateness" (p. 64).

The analyses of moves/steps patterns and lexical bundles suggest several pedagogical implications for novice writers, graduate students, and non-native English writers in relation to teaching English for academic or specific purposes. This type of analytical comparison helps raise students' and novice writers' awareness of specific practices and norms in local and international contexts in different fields, including applied linguistics. Furthermore, rhetorical structures and variations in English research articles need to be taught explicitly to graduate students in academic writing or academic writing for publication courses. For instance, learners should be exposed to class activities with writing samples and assignments that illustrate the variety of academic genres across academic disciplines based on the students' needs.

Practitioners and course designers of English for academic and specific disciplines could benefit from the list of lexical bundles identified in the study - See Appendix D. However, since the lexical bundles occur and behave differently in each discipline (Hyland, 2008b), it is crucial that these bundles be dealt with cautiously. Academic writing teachers can take advantage of the structural and functional classification procedures and production tasks (e.g., familiarization with form and function) to help their students identify and employ the specific types and rhetorical functions of certain lexical bundles (Hyland, 2008b; Neely \& Cortes, 2009).

The present study has its limitations. First, while determining boundaries between larger chunks (introduction, theoretical background...) is usually easy to do, deciphering the boundaries between the steps is not transparent and can be very tricky. Therefore, the present study concentrated more on boundaries between larger chunks, leaving the analysis of boundaries between steps for future investigations. Second, the present study used specialized corpora that had only 30 RAs (15 from each corpus). Using a large-scale corpus in future research could increase its representativeness and may reveal different results. Furthermore, it is recommended that future investigations include conducting interviews with the authors of the articles, especially in the Saudi journals. The aim of the interviews would be to inquire about the authors' perceptions of the employment of certain move patterns and lexical bundles and the absence of others. Since the scope of the study was limited, the interviewers could investigate only some of the aspects related to educational and cultural backgrounds, writing and publishing experience, and the involvement of native speakers in the process of writing and publishing the articles (Alamri, 2017).

The potential cross-linguistic influence of first language (L1) on employing lexical bundles has also been highlighted in the literature (Ädel \& Erman, 2012; Chen \& Baker, 2010). For instance, L1 influence has been observed in a few languages, including Hebrew (Laufer \& Waldman, 2011), French (Paquot, 2013), Spanish (Pérez-Llantada, 2014), Turkish (Güngö, 2016), and Persian (Esfandiari \& Barbary, 2017). To the best of my knowledge, no contrastive analyses of lexical bundles in the Arabic language have been conducted yet. An investigation of L1 Arabic influence on retrieving and employing lexical bundles when writing English research articles would therefore be very interesting, especially in a three-way comparison of lexical bundles among L1 Arabic, L1 English, and L2 English writers. 


\section{Acknowledgments}

I would like to thank Todd Ruecker and the anonymous reviewers for their suggestions and comments on this study.

\section{References}

Ädel,A., \& Erman, B. (2012). Recurrent word combinations in academic writing by native and non-native speakers of English: A lexical bundles approach. English for Specific Purposes, 31(2), 81-92. https://doi.org/10.1016/j. esp.2011.08.004

Adel, S. M. R., \& Moghadam, R. G. (2015). A comparison of moves in conclusion sections of research articles in psychology, Persian literature and applied linguistics. Teaching English Language, 9(2), 167-191. https://doi. org/10.22132/tel.2015.53729

Alamri, B. M. (2017). Connecting genre-based and corpus-driven approaches in research articles: A comparative study of moves and lexical bundles in Saudi and international journals [Doctoral dissertation, University of New Mexico]. ProQuest Dissertations \& Theses Global.

Alharbi, L. M., \& Swales, J. M. (2011). Arabic and English abstracts in bilingual language science journals: Same or different? Languages in Contrast, 11(1), 70-86. https://doi.org/10.1075/lic.11.1.06alh

Alhuqbani, M. N. (2012). A cross-cultural analysis of moves in Arabic and English police and security research article abstracts. In Proceedings ot the 2nd International Conference on Foreign Language Teaching and Applied Linguistics. Sarajevo. https://doi.org/10.12816/0018001

Alhuqbani, M. N. (2013). Genre-based analysis of Arabic research article abstracts across four disciplines. Journal of Educational and Social Research, 3(3), 371-379. https://doi.org/10.5901/jesr.2013.v4n3p371

Alotaibi, H. (2013). Research article abstracts and introductions: A comparative genre-based study of Arabic and English in the fields of educational psychology and sociology [Doctoral dissertation, Texas A\&M UniversityCommerce]. ProQuest Dissertations \& Theses Global.

Alotaibi, H., \& Pickering, L. (2013). Cultural divergence in academic writing: A case study of the research article introduction in Arabic. The Global e-Learning Journal, 2(4), 1-19.

Al-Qahtani, A. (2006). A contrastive rhetoric study of Arabic and English research article introductions [Doctoral dissertation, Oklahoma State University]. ProQuest Dissertations \& Theses Global.

Altenberg, B. (1998). On the phraseology of spoken English: The evidence of recurrent word-combinations [G]. In A. P. Cowie (Ed.), Phraseology: Theory, analysis and applications (pp. 101-122). Oxford University Press.

Amnuai, W. (2012). A comparative study of English applied linguistics research articles between Thai and internationally published journals: Moves and formulaic sequences [Unpublished doctoral dissertation]. Suranaree University of Technology.

Amnuai, W., \& Wannaruk, A. (2013a). Investigating move structure of English applied linguistics research article discussions published in international and Thai journals. English Language Teaching, 6(2), 1-13. https://doi. org/10.5539/elt.v6n2p1

Amnuai, W., \& Wannaruk, A. (2013b). A move-based analysis of the conclusion sections of research articles published in international and Thai journals. Language, Linguistics and Literature, The Southeast Asian Journal of English Language Studies, 19(2), 53-63.

Bhatia, V. (1993). Analyzing genre: Language use in professional settings. Longman.

Biber, D. (2009). A corpus-driven approach to formulaic language in English: Multi-word patterns in speech and writing. International Journal of Corpus Linguistics, 14(3), 275-311. https://doi.org/10.1075/ijcl.14.3.08bib

Biber, D., \& Barbieri, F. (2007). Lexical bundles in university spoken and written registers. English for Specific Purposes, 26(3), 263-286. https://doi.org/10.1016/j.esp.2006.08.003

Biber, D., Connor, U., \& Upton, T. A. (2007). Discourse on the move using corpus analysis to describe discourse structure. John Benjamins Pub. Co.

Biber, D., \& Conrad, S. (1999). Lexical bundles in conversation and academic prose. In H. Hasselgard \& S. Oksefjell (Eds.), Out of Corpora (pp. 181-190). Rodopi.

Biber, D., Conrad, S., \& Cortes, V. (2004). If you look at...: Lexical bundles in university teaching and textbooks. Applied Linguistics, 25(3), 371-405. https://doi.org/10.1093/applin/25.3.371

Biber, D., \& Gray, B. (2015). Grammatical complexity in academic English: Linguistic change in writing. Cambridge 
University Press. https://doi.org/10.1093/applin/25.3.371

Biber, D., Johansson, S., Leech, G., Conrad, S., Finegan, E., \& Quirk, R. (1999). Longman grammar of spoken and written English (vol. 2). MIT Press.

Brett, P. (1994). A genre analysis of the results section of sociology articles. English for Specific Purposes, 13(1), 47-59. https://doi.org/10.1016/0889-4906(94)90024-8

Chen, Y.-H., \& Baker, P. (2010). Lexical bundles in L1 and L2 academic writing. Language Learning \& Technology, 14(2), 30-49.

Cheng, A. (2006). Understanding learners and learning in ESP genre-based writing instruction. English for Specific Purposes, 25(1), 76-89. https://doi.org/10.1016/j.esp.2005.07.002

Cocal, C., \& De Vera, I. (2018). Challenges and Strategies on Paper Publication to International Indexed Journals by Filipino Academic Researchers. Asian ESP Journal, 14(7.2), 113-131.

Cortes, V. (2013). The purpose of this study is to: Connecting lexical bundles and moves in research article introductions. Journal of English for Academic Purposes, 12(1), 33-43. https://doi.org/10.1016/j. jeap.2012.11.002

Cotos, E., Huffman, S., \& Link, S. (2017). A move/step model for methods sections: Demonstrating Rigour and Credibility. English for Specific Purposes, 46, 90-106. https://doi.org/10.1016/j.esp.2017.01.001

Dudley-Evans, T. (1994). Genre analysis: An approach to text analysis for ESP. In M. Coultard (Ed.), Advances in written text analysis (pp. 219-228). Routledge.

Dudley-Evans, T., \& John, M. (1998). Developments in English for Specific Purposes. Cambridge University Press.

Esfandiari, R., \& Barbary, F. (2017). A contrastive corpus-driven study of lexical bundles between English writers and Persian writers in psychology research articles. Journal of English for Academic Purposes, 29, 21-42. https://doi.org/10.1016/j.jeap.2017.09.002

Fakhri, A. (2004). Rhetorical properties of Arabic research article introductions. Journal of Pragmatics, 36(6), 1119-1138. https://doi.org/10.1016/j.pragma.2003.11.002

Fallatah, W. (2016). Features of Saudi English research articles abstracts. Arab World English Journal (AWEJ), 7(2), 368-379. https://doi.org/10.24093/awej/vol7no2.25

Friginal, E., \& Mustafa, S. S. (2017). A comparison of U.S.-based and Iraqi English research article abstracts using corpora. Journal of English for Academic Purposes, 25, 45-57. https://doi.org/10.1016/j.jeap.2016.11.004

Güngö, F. (2016). Cross-linguistic analysis of lexical bundles in L1 English, L2 English, and L1 Turkish research ]] Unpublished doctoral dissertation), Gazi University.

Gungor, F., \& Uysal, H. H. (2016). A comparative analysis of lexical bundles used by native and non-native scholars. English Language Teaching, 9(6), 176-188. https://doi.org/10.5539/elt.v9n6p176

Habibie, P., \& Hyland, K. (2019). Novice Writers and Scholarly Publication: Authors, Mentors, Gatekeepers. Palgrave Macmillan.

Halliday, M. A. (1989). Some grammatical problems in scientific English. Australian Review of Applied Linguistics. Supplement Series, 6(1), 13-37. https://doi.org/10.1075/aralss.6.02hal

Hirano, E. (2009). Research article introductions in English for specific purposes: A comparison between Brazilian Portuguese and English. English for Specific Purposes, 28(4), 240-250. https://doi.org/10.1016/j. esp.2009.02.001

Holmes, R. (1997). Genre analysis, and the social sciences: An investigation of the structure of research article discussion sections in three disciplines. English for Specific Purposes, 16(4), 321-337. https://doi.org/10.1016/ s0889-4906(96)00038-5

Hyland, K. (2000). Disciplinary discourses: Social interactions in academic writing (Michigan classics ed.). University of Michigan Press.

Hyland, K. (2004). Genre and second language writing. University of Michigan Press.

Hyland, K. (2008a). Genre and academic writing in the disciplines. Language Teaching, 41(4), 543-562. https:// doi.org/10.1017/s0261444808005235

Hyland, K. (2008b). As can be seen: Lexical bundles and disciplinary variation. English for Specific Purposes, 27(1), 4-21. https://doi.org/10.1016/j.esp.2007.06.001

Hyland, K. (2012). Bundles in academic discourse. Annual Review of Applied Linguistics, 32, 150-169. https://doi. org/10.1017/s0267190512000037

Hyland, K. (2015). Academic publishing: Issues and challenges in the construction of knowledge. Oxford University Press.

Hyland, K. (2016). Academic publishing and the myth of linguistic injustice. Journal of Second Language Writing, 31, 58-69. https://doi.org/10.1016/j.jslw.2016.01.005

Hyland, K., \& Tse, P. (2005). Hooking the reader: a corpus study of evaluative that in abstracts. English for Specific 
Purposes, 24(2), 123-139. https://doi.org/10.1016/j.esp.2004.02.002

Itakura, H., \& Tsui, A. B. M. (2011). Evaluation in academic discourse: Managing criticism in Japanese and English book reviews. Journal of Pragmatics, 43(5), 1366-1379. https://doi.org/10.1016/j.pragma.2010.10.023

Kanoksilapatham, B. (2005). Rhetorical structure of biochemistry research articles. English for Specific Purposes, 24(3), 269-292. https://doi.org/10.1016/j.esp.2004.08.003

Kwan, B. S. C. (2006). The schematic structure of literature reviews in doctoral theses of applied linguistics. English for Specific Purposes, 25(1), 30-55. https://doi.org/10.1016/j.esp.2005.06.001

Laufer, B., \& Waldman, T. (2011). Verb-noun collocations in second language writing: A corpus analysis of learners' English. Language Learning, 61(2), 647-672. https://doi.org/10.1111/j.1467-9922.2010.00621.x

Le, T. N.P., \& Harrington, M. (2015). Phraseology used to comment on results in the Discussion section of applied linguistics quantitative research articles. English for Specific Purposes, 39, 45-61. https://doi.org/10.1016/j. esp.2015.03.003

Lorés-Sanz, R. (2016). ELF in the making? Simplification and hybridity in abstract writing. Journal of English as a Lingua Franca, 5(1), 53-81. https://doi.org/10.1515/jelf-2016-0003

Mahboob, A., \& Elyas, T. (2014). English in the Kingdom of Saudi Arabia. World Englishes, 33(1), 128-142. https:// doi.org/10.1111/weng.12073

Mauranen, A. (2007). Hybrid voices: English as the lingua franca of academics. In K. Flottum (Ed.), Language and discipline perspectives on academic discourse (pp. 244-259). Cambridge Scholars Publishing.

Mizumoto, A., Hamatani, S., \& Imao, Y. (2017). Applying the bundle-move connection approach to the development of an online writing support tool for research articles: Using bundle-move connection for tool development. Language Learning, 67(4), 885-921. https://doi.org/10.1111/lang.12250

Moldovan, C. (2011). Writing a scientific paper in English-challenges and common errors. Revista Română de Medicină de Laborator, 19(4), 391-394.

Morales, R. C. (2012). Conclusions in research articles: A Filipino-Japanese contrastive rhetoric study. Philippines ESL Journal, 8, 83-95.

Moritz, M. E., Meurer, J., \& Dellagnelo, A. K. (2008). Conclusions as components of research articles across Portuguese as a native language, English as a native language and English as a foreign language: A contrastive genre study. The ESPecialist, 29(2), 233-253.

Neely, E., \& Cortes, V. (2009). A little bit about: Analyzing and teaching lexical bundles in academic lectures. Language Value, 1(1), 17-38.

Nwogu, K. N. (1997). The medical research paper: Structure and functions. English for Specific Purposes, 16(2), 119-138. https://doi.org/10.1016/s0889-4906(97)85388-4

Ozturk, I. (2007). The textual organization of research article introductions in applied linguistics: Variability within a single discipline. English for Specific Purposes, 26(1), 25-38.https://doi.org/10.1016/j.esp.2005.12.003

Pan, F., Reppen, R., \& Biber, D. (2015). Comparing patterns of L1 versus L2 English academic professionals: Lexical bundles in telecommunications research journals. Journal of English for Academic Purposes, 21, 60-71. https://doi.org/10.1016/j.jeap.2015.11.003

Paquot, M. (2013). Lexical bundles and L1 transfer effects. International Journal of Corpus Linguistics, 18(3), 391417. https://doi.org/10.1075/ijcl.18.3.06paq

Peacock, M. (2011). The structure of the methods section in research articles across eight disciplines. Asian ESP Journal, 7(2), 97-124.

Pérez-Llantada, C. (2014). Formulaic language in L1 and L2 expert academic writing: Convergent and divergent usage. Journal of English for Academic Purposes, 14, 84-94. https://doi.org/10.1016/j.jeap.2014.01.002

Pho, P. D. (2008). How can learning about the structure of research articles help international students? Conference proceedings of the 19th ISANA international education conference (vol. 2, pp. 1-11). Citeseer.

Posteguillo, S. (1999). The schematic structure of computer science research articles. English for Specific Purposes, 18(2), 139-160. https://doi.org/10.1016/s0889-4906(98)00001-5

Ruiying, Y., \& Allison, D. (2003). Research articles in applied linguistics: Moving from results to conclusions. English for Specific Purposes, 22(4), 365-385. https://doi.org/10.1016/s0889-4906(02)00026-1

Ruiying, Y., \& Allison, D. (2004). Research articles in applied linguistics: Structures from a functional perspective. English for Specific Purposes, 23(3), 264-279. https://doi.org/10.1016/s0889-4906(03)00005-x

Sandoval, M. (2010). Stance-taking strategies in the written discourse of research papers conclusion sections. First International TESOL Convention (Vol. 3, p. 2011). Clark Freeport Zone.

Stefanowitsch, A. (2018). Corpus linguistics: A guide to the methodology. Language Science Press.

Swales, J. (1990). Genre analysis: English in academic and research settings. Cambridge University Press.

Swales, J. (2004). Research genres: Explorations and applications. Cambridge University Press. 


\section{BASIM ALAMRI}

Swales, J., \& Feak, C. (2009). Abstracts and the writing of abstracts. University of Michigan Press.

Tardy, C. M. (2019). We are all reviewer \#2: A window into the secret world of peer review. In P. Habibie \& K. Hyland (Eds), Novice writers and scholarly publication: Authors, mentors, gatekeepers (pp. 271-289). Palgrave Macmillan.

Thompson, P., \& Tribble, C. (2001). Looking at citations: Using corpora in English for academic purposes. Language Learning and Technology, 5(3), 91-105.

Vuković, M., \& Bratic, V. (2015). The rhetorical structure of conclusions in linguistic academic articles published in national and international journals. In I. Lakić, B. Živković \& M. Vuković (Eds.), Academic discourse across cultures (pp. 87-96). Cambridge Scholars Publishing.

$\mathrm{Xu}, \mathrm{F}$. (2019). Learning the language to write for publication: The nexus between the linguistic approach and the genre approach. In P. Habibie \& K. Hyland (Eds). Novice writers and scholarly publication: Authors, mentors, gatekeepers (pp. 117-134). Palgrave Macmillan.

Yoon, C., \& Choi, J.-M. (2015). Lexical bundles in Korean university students' EFL compositions: A comparative study of register and use.Modern English Education, 16(3),47-69.https://doi.org/10.18095/meeso.2015.16.3.03 


\section{Appendix A}

\section{List of Research Articles Used for the Analyses}

\section{The International Corpus}

I1 Mulder, K., \& Hulstijn, J. H. (2011). Linguistic skills of adult sative Speakers, as a function of age and level of education. Applied Linguistics, 32(5), 475-494.

I2 Lee Amuzie, G., \& Spinner, P. (2013). Korean EFL learners' indefinite article use with four types of abstract nouns. Applied Linguistics, 34(4), 415-434.

*I3 Gablasova, D. (2015). Learning technical words through L1 and L2: Completeness and accuracy of word meanings. English for Specific Purposes, 39, 62-74.

*I4 Stapleton, P. (2012). Gauging the effectiveness of anti-plagiarism software: An empirical study of second language graduate writers. Journal of English for Academic Purposes, 11(2), 125-133.

I5 Junqueira, L. (2013). A genre-based investigation of applied linguistics book reviews in English and Brazilian Portuguese. Journal of English for Academic Purposes, 12(3), 203-213.

I6 Neumann, H. (2014). Teacher assessment of grammatical ability in second language academic writing: A case study. Journal of Second Language Writing, 24, 83-107.

"I7 Li, M., \& Kim, D. (2016). One wiki, two groups: Dynamic interactions across ESL collaborative writing tasks. Journal of Second Language Writing, 31, 25-42.

I8 Simard, D., \& Jean, G. (2011). An exploration of 12 teachers' use of pedagogical interventions devised to draw L2 Learners' attention to form: Exploration of L2 teachers' use of pedagogical interventions. Language Learning, 61(3), 759-785.

I9 Webb, S., Newton, J., \& Chang, A. (2013). Incidental learning of collocation: Incidental learning of collocation. Language Learning, 63(1), 91-120.

I10 Golonka, E., Bowles, A., Silbert, N., Kramasz, D., Blake, C., \& Buckwalter, T. (2015). The role of context and cognitive effort in vocabulary learning: A study of intermediate-level learners of Arabic. The Modern Language Journal, 99(1), 19-39.

I11 Davis, J. M. (2016). Toward a capacity framework for useful student learning outcomes assessment in college foreign language programs. The Modern Language Journal, 100(1), 377-399.

I12 Ortega-Llebaria, M., \& Colantoni, L. (2014). L2 English intonation. Studies in Second Language Acquisition, 36(2), 331-353.

I13 Yalçın, Ş., \& Spada, N. (2016). Language aptitude and grammatical difficulty. Studies in Second Language Acquisition, 38(2), $239-263$.

I14 Buckingham, L. (2014). Building a career in English: Users of English as an additional language in academia in the Arabian Gulf. TESOL Quarterly, 48(1), 6-33.

I15 Tum, D. O. (2015). Foreign language anxiety's forgotten study: The case of the anxious preservice teacher. TESOL Quarterly, 49(4), 627-658.

* Articles coded for intercoder reliability

\section{The Saudi Corpus}

S1 Bani Abdelrhman, O. N. M. (2013). The use of the whole language approach to sharpen EFL learners' writing skill at Al - Imam Muhammad Bin Saud Islamic University. Journal of Humanities and Social Studies, (30), 1-30.

S2 Alharbi, M. (2015). The effects of using the reading thinking activity model (RTAM) on reading comprehension: A case study of the preparatory year students at IMISU, Saudi Arabia. Journal of Humanities and Social Studies, (35), 101-136.

S3 Maghrabi, R. O. (2013). Tongue twisters in English: A psycholinguistic investigation of the relationship between language production of Saudi ESL and verbal working memory. Journal of King Abdulaziz University. Arts and Humanities, 21, 165-197.

"S4 Alqurashi, F. (2015). The effect of peer response groups on EFL college writing students' perceived peer social support. Scientific Journal of King Faisal University. Humanities and Management Sciences, 16(1), 189-199.

S5 Abanomey, A. A. (2013). Do EFL Saudi learners perform differently with online reading? An exploratory study. Journal of King Saud University - Languages and Translation, 25(1), 1-11.

"S6 Abdellah, A. (2013). Training Saudi English majors in extensive reading to develop their standard-based reading skills. Journal of King Saud University - Languages and Translation, 25(1), 13-20.

S7 Alshumaim, Y., \& Alhassan, R. (2013). Current availability and use of ICT among secondary EFL teachers in Saudi Arabia: Possibilities and reality. Journal of Educational Sciences, 25(1), 225-238.

S8 Bamanger, E. M., \& Gashan, A. K. (2015). The effect of planning time on the fluency, accuracy, and complexity of EFL learners' oral production. Journal of Educational Sciences, 27(1), 161-175.

S9 Al-Seghayer, K. (2014). The impact of gender and reading proficiency level on online reading strategies employed by EFL learners. Journal of Educational Sciences, 26(2), 493-509. 


\section{BASIM ALAMRI}

S10 Shatnawi, M. M. K. (2016). The effectiveness of the inductive versus deductive methods in teaching passive voice to first secondary students in Al-Ahsa. Journal of the North for Humanities, 1(2), 201-212.

S11 Alrajhi, A. M., Abdelrahman, O. N. M. B., \& Al Homoud, F. A. (2014). The effect of using drama on improving preparatory year students' oral proficiency at Al-Imam Muhammad Ibn Saud Islamic University. Qassim University Journal of Arabic and Human Sciences, 7(1), 25-50.

S12 Al-Rojaie, Y. I. (2012). Saudi EFL reading teachers' pedagogical beliefs and practices: A qualitative case study. Qassim University Journal of Arabic and Human Sciences, 5(1), 1-19.

"S13 Al Fageeh, A. (2014). Effects of using wikis for developing Saudi EFL students' reading and writing skills. Umm Al-Qurma University Journal of Languages and Literatures, 14, 9-37.

S14 Alrefaai, I. K., Rab, S. D. A., \& Islam, M. S. (2013). The general study habits of major EFL students in King Khalid University and their relationships with GPA, gender and certain social factors. Umm Al-Qura University Journal of Languages and Literatures, 10, 9-63.

S15 Jahin, J. H., \& Idrees, M. (2012). EFL major student teachers' writing proficiency and attitudes towards learning English. Umm AlQura University Journal of Educational \& Psychologic Sciences, 4(1), 10-72.

* Articles coded for intercoder reliability 


\section{Appendix B}

\section{Biber's et al.'s Structural Taxonomy (Biber, Conrad, \& Cortes, 2004)}

Structural types of lexical bundles (Biber et al., 1999, pp. 997-1025).

\begin{tabular}{|c|c|c|}
\hline Category & Pattern & Examples \\
\hline \multirow{2}{*}{ NP-based } & Noun phrase + of & the end of the, the nature of the, the beginning of the, a large number of \\
\hline & Other Noun phrases & the fact that the, one of the most, the extent to which, an important role in \\
\hline \multirow{2}{*}{ PP-based } & Prepositional phrase + of & at the end of, as a result of, on the basis of, in the context of \\
\hline & Other prepositional phrases & on the other hand, at the same time, in the present study, with respect to the \\
\hline \multirow{7}{*}{ VP-based } & $\mathrm{Be}+$ noun/adjective phrases & is the same as, is a matter of, is due to the, be the result of, is a significant difference \\
\hline & Passive verb + prep. phrase fragments & is shown in figure, is based on the, is defined as the, can be found in \\
\hline & Anticipatory it + verb/adjective phrases & it is important to, it is possible that, it was found that, it should be noted \\
\hline & (Verb phrase) + that-clause fragments & should be noted that, that this is a, we assume that the \\
\hline & (Verb/adjective) + to-clause fragments & are likely to be, to be able to, to determine whether the \\
\hline & Adverbial clause fragments & as shown in table, if there is a, as can be seen in, as compared with the \\
\hline & Pronoun/noun phrase + be $(+\ldots)$ & this is not the, there was no difference, this is the first \\
\hline $\begin{array}{l}\text { Other } \\
\text { expressions }\end{array}$ & Other & did not differ between, as well as the \\
\hline
\end{tabular}


BASIM ALAMRI

\section{Appendix C}

\section{Hyland's (2008b) Discourse Functional Taxonomy}

\section{Hyland's (2008) Discourse Functions Taxonomy (pp. 13-14)}

\begin{tabular}{|c|c|}
\hline Category & Examples \\
\hline \multicolumn{2}{|c|}{ Research-oriented - help writers to structure their activities and experiences from the real world } \\
\hline Location - indicating time/place & (at the beginning of, in the present study). \\
\hline Procedure & (the role of the, the purpose of the). \\
\hline Quantification & (the magnitude of the, a wide range of,). \\
\hline Description & (the structure of the, the size of the). \\
\hline Topic - related to the field of research & (in the Hong Kong, the currency board system). \\
\hline \multicolumn{2}{|c|}{ Text-oriented - concerned with the organization of the text and its meaning as a message } \\
\hline \multicolumn{2}{|c|}{$\begin{array}{l}\text { Transition signals - establishing additive or contrastive links between elements } \\
\text { (on the other hand, in addition to the, in contrast to the). }\end{array}$} \\
\hline \multicolumn{2}{|c|}{$\begin{array}{l}\text { Resultative signals - mark inferential or causative relations between elements } \\
\text { (as a result of, it was found that, these results suggest that). }\end{array}$} \\
\hline $\begin{array}{l}\text { Structuring signals - text-reflex } \\
\text { the text } \\
\text { (in the present study, in the next }\end{array}$ & $\begin{array}{l}\text { which organize stretches of discourse or direct reader elsewhere in } \\
\text { own in figure). }\end{array}$ \\
\hline \multicolumn{2}{|c|}{$\begin{array}{l}\text { Framing signals - situate arguments by specifying limiting conditions } \\
\text { (in the case of, on the basis of, in the presence of, with the exception of). }\end{array}$} \\
\hline \multicolumn{2}{|c|}{ Participant-oriented - these are focused on the writer or reader of the text } \\
\hline \multicolumn{2}{|c|}{$\begin{array}{l}\text { Stance features - convey the writer's attitudes and evaluations } \\
\text { (are likely to be, may be due to, it is possible that). }\end{array}$} \\
\hline $\begin{array}{l}\text { Engagement features - address readers directly } \\
\text { (it should be noted that, as can be seen). }\end{array}$ & \\
\hline
\end{tabular}




\title{
Appendix D
}

\section{List of Lexical Bundles Associated with Each Move in both Corpora}

\begin{tabular}{|c|c|}
\hline & International corpus \\
\hline $\begin{array}{c}\text { Move } 1 \\
\text { Establishing a territory }\end{array}$ & $\begin{array}{l}\text { on the other hand, one of the most, this } \\
\text { line of research, as one of the, it is well } \\
\text { established that }\end{array}$ \\
\hline $\begin{array}{c}\text { Move } 2 \\
\text { Establishing a niche }\end{array}$ & $\begin{array}{l}\text { little is known about, as a result of, as well } \\
\text { as the, in the case of, the fact that the, to } \\
\text { the effects of, are likely to be, the results } \\
\text { indicated that, in the context of, in the } \\
\text { present study, on the other hand, research } \\
\text { has shown that, a limited number of, about } \\
\text { the meaning of, and a lack of, as well as } \\
\text { their, can be seen in, however very little is, } \\
\text { on the basis of, that the majority of, that } \\
\text { the number of, that there is a, the effect of } \\
\text { the, the extent to which, the form of a, the } \\
\text { meaning of a, the nature of the, there has } \\
\text { been little, this line of research, were based } \\
\text { on a, with the acquisition of, }\end{array}$ \\
\hline
\end{tabular}

\author{
Saudi corpus
}

one of the most, as well as the, at the same time, based on the assumption, is one of the, on the other hand on the other hand, the results of the, the extent to which, in the use of, significant differences between the, that there was no the results showed that, the study showed that, the use of the, as well as the, a wide range of, that the use of, a number of researchers, a number of studies, can be used to, significant difference between the, that the majority of, that there is a, the degree to which, the effectiveness of the, the researcher found that, a study in which, the effect of the, the results indicated that, the study consisted of, from a variety of, no significant differences between, on the basis of, the basis of the, the results of a, at the end of, have been conducted on, in the case of, on the effect of, this study aimed at, a handful of studies, about the use of, are likely to be, as a function of, as a tool to, as the design of, can be utilized in, differ widely from the, divided into two parts, from the current study, has been carried out, has been conducted on, in addition to the, in relation to their, in the field of, in the process of, in their use of, is devoted to the, is divided into two, is due to the, it was found that, that most of the, the beginning of the, the best knowledge of, the design of studies, the results show that, the study revealed that, there is a need, they were asked to, to a variety of, were divided into two, were exposed to the, when compared to the

Move 3

Presenting the Present Work the following research questions, on the other hand, the extent to which, intends to contribute to, the following research question, the study addressed the, to shed light on the significance of the, aims at exploring the, in relation to the, the use of the, the effect of the, the effect of using, in the field of, to shed light on the, a wide range of, addressed the following research, answer the following questions, in favor of the, in the context of, in the process of, it is hoped that, on the effect of, over a period of time, the effects of the, the gap in the, the impact of the, the present study investigated, the purpose of the, the results of the, this study aims at, were exposed to the

\begin{tabular}{|c|c|c|}
\hline $\begin{array}{l}\text { Move } 4 \\
\text { Overview }\end{array}$ & -- & $\begin{array}{l}\text { for the purpose of, in the present study, the effectiveness of } \\
\text { the, this study utilized a }\end{array}$ \\
\hline $\begin{array}{l}\text { Move } 5 \\
\text { Location }\end{array}$ & the study was conducted in & \\
\hline $\begin{array}{c}\text { Move } 7 \\
\text { Subjects/Materials }\end{array}$ & $\begin{array}{l}\text { on the basis of, it was not possible, for each } \\
\text { of the, a focus on the, a high degree of, a wide } \\
\text { range of, can be found in, in addition to the, } \\
\text { in order to explore, the purpose of the, the } \\
\text { study was conducted, }\end{array}$ & $\begin{array}{l}\text { to a sample of, the purpose of the, was developed by the, } \\
\text { was taught by the, as shown in table, in the present study, on } \\
\text { the other hand, one of the most, to a number of, }\end{array}$ \\
\hline $\begin{array}{c}\text { Move } 8 \\
\text { Procedures }\end{array}$ & $\begin{array}{l}\text { at the beginning of the, at the end of, in the } \\
\text { current study, the purpose of the, they } \\
\text { were asked to, were included in the, }\end{array}$ & $\begin{array}{l}\text { students were asked to, the purpose of the, the study was } \\
\text { conducted, they were asked to, }\end{array}$ \\
\hline $\begin{array}{c}\text { Move } 10 \\
\text { Data Analysis }\end{array}$ & $\begin{array}{l}\text { in the present study, the analysis of the, the } \\
\text { meaning of the, as well as the, at the same } \\
\text { time, can be seen in, in order to determine, in } \\
\text { the case of, the reliability of the, with respect } \\
\text { to the, }\end{array}$ & the number of errors \\
\hline $\begin{array}{l}\text { Move } 11 \\
\text { Preparatory information }\end{array}$ & -- & at the beginning of the, in order to ensure \\
\hline
\end{tabular}




\begin{tabular}{|c|c|c|}
\hline $\begin{array}{c}\text { Move } 12 \\
\text { Reporting results }\end{array}$ & $\begin{array}{l}\text { the rest of the, in the same way, are } \\
\text { presented in table, can be seen in, in relation } \\
\text { to the, statistically significant difference } \\
\text { between, was found in the, are reported } \\
\text { in table, in each of the, in terms of their, } \\
\text { it is important to, of the number of, one of } \\
\text { the main, the following excerpts illustrate, } \\
\text { the majority of the, the results for the, the } \\
\text { results of the, there was a significant, was } \\
\text { also reflected in, were observed in the, }\end{array}$ & $\begin{array}{l}\text { the results of the, the mean scores of, as shown in table, are } \\
\text { shown in table, that there is a, in favor of the, statistically } \\
\text { significant difference at, on the other hand, it shows that the, } \\
\text { statistically significant difference between, that there } \\
\text { was a, the majority of the, in favour of the, as seen in table, } \\
\text { the results of this, and in favor of, in each of the, in order } \\
\text { to make, in terms of the, of the sample of, that the difference } \\
\text { in, the main idea of, the mean score for, the meaning of the }\end{array}$ \\
\hline $\begin{array}{c}\text { Move } 13 \\
\text { Commenting on results }\end{array}$ & $\begin{array}{l}\text { on the other hand, did not result in, in the } \\
\text { case of, }\end{array}$ & $\begin{array}{l}\text { the mean scores of, in favour of the, to the effect of, be } \\
\text { attributed to the, in the control group, in the experimental } \\
\text { group, it also supports the, supports the premise that, that } \\
\text { there were no, the results of the, }\end{array}$ \\
\hline $\begin{array}{c}\text { Move } 14 \\
\text { Summarizing results }\end{array}$ & -- & it is clear from \\
\hline $\begin{array}{l}\text { Move } 15 \\
\text { Evaluating the study }\end{array}$ & -- & the main goal of, \\
\hline $\begin{array}{c}\text { Move } 18 \\
\text { Reporting results }\end{array}$ & $\begin{array}{l}\text { in the present study, as can be seen, in the } \\
\text { case of, in the sense that, the case with the, } \\
\text { the data show that, the results of the, the } \\
\text { results revealed that, the results showed that, } \\
\text { with respect to vocabulary, }\end{array}$ & $\begin{array}{l}\text { a significant difference in, in terms of the, the results } \\
\text { indicate that, a positive correlation between, the beginning } \\
\text { of the, the results of the, }\end{array}$ \\
\hline $\begin{array}{c}\text { Move } 19 \\
\text { Summarizing results }\end{array}$ & -- & the findings of the study, \\
\hline $\begin{array}{c}\text { Move } 20 \\
\text { Commenting on results }\end{array}$ & $\begin{array}{l}\text { on the other hand, it is important to, is } \\
\text { in line with, in the present study, it should } \\
\text { be noted, are in line with, it is possible that, } \\
\text { the ease with which, the findings of the, } \\
\text { this is consistent with, the findings of this, } \\
\text { with respect to the, a higher number of, are } \\
\text { likely to be, as well as to, at the same time, } \\
\text { could be used to, did not appear to, does not } \\
\text { seem to, in line with the, in terms of the, } \\
\text { in the field of, of most of the, one possible } \\
\text { explanation is that, that the nature of, the } \\
\text { degree to which, the extent to which, the fact } \\
\text { that the, the meaning of the, the results of } \\
\text { this, to note that the, }\end{array}$ & $\begin{array}{l}\text { the results of the, on the other hand, can be attributed to, } \\
\text { with the findings of, by the fact that, could be attributed to, in } \\
\text { favor of the, be due to the, a wide range of, as discussed in the, } \\
\text { at the same time, can be explained by, due to the fact that, } \\
\text { from the fact that, is consistent with the, it is important to, } \\
\text { it was clear that, might be due to, on the part of, significant } \\
\text { differences between the, significant improvement on the, } \\
\text { study revealed that the, the results of this, to the fact that, } \\
\text { with the results of, }\end{array}$ \\
\hline $\begin{array}{l}\text { Move } 22 \\
\text { Evaluating the study }\end{array}$ & $\begin{array}{l}\text { a starting point for, in the present study, on } \\
\text { the other hand, with respect to the, }\end{array}$ & the results of the, \\
\hline $\begin{array}{l}\text { Move } 23 \\
\text { Deductions from the } \\
\text { research }\end{array}$ & $\begin{array}{l}\text { the results of this, this study suggest that, to } \\
\text { be the most, }\end{array}$ & as well as the, \\
\hline $\begin{array}{l}\text { Move } 24 \\
\text { Summarizing the study }\end{array}$ & -- & that there is a, the study showed that, \\
\hline $\begin{array}{c}\text { Move } 26 \\
\text { Deductions from the } \\
\text { research }\end{array}$ & $\begin{array}{l}\text { future research could examine, research has } \\
\text { shown that, to better understand the, }\end{array}$ & $\begin{array}{l}\text { in light of the, the findings of the, are recommended to do } \\
\text { the, carry out further research, conduct further studies } \\
\text { concerning, in the area of, in their knowledge of, is one of } \\
\text { the, on the use of, research is needed to, should be conducted } \\
\text { to, should believe in the, should try to be, the findings of this, } \\
\text { the results of this, the usefulness of the, to determine the } \\
\text { most, to do the following, }\end{array}$ \\
\hline
\end{tabular}

Bold = bundle occurs in both corpora 